correct in only $52 \cdot 3 \%$ of cases, and $10 \%$ of children with a temperature of $38.9^{\circ} \mathrm{C}$ or higher were incorrectly identified as being afebrile. ${ }^{18}$ Other studies found that nurses and doctors were also poor at identifying the presence of fever in children. ${ }^{319}$

General practitioners clean their thermometers in a variety of ways, and several doctors admitted to not cleaning them at all. This raises concern for the risk of cross infection. One doctor used thermometer sheaths, which are placed over the thermometer before use and disposed of after use. I am not aware of any studies that have looked into the effect of these thermometer sheaths on the accuracy of the temperature readings.

A doctor might take a patient's temperature for many reasons, but no conclusions can be made as to their importance. One reason brought to light in this study is medicolegal; however, the secretary of one of the defence societies was unable to give any examples of a doctor being found negligent simply for failing to take a patient's temperature. He did qualify this by stating that doctors may be questioned very closely about their reasons for not taking a patient's temperature and, taken with other factors, this may swing a decision for disciplinary proceedings against the doctor.

I thank Dr Nigel Hague for his help and support.
1 Coggon DNM, Vessey MP. Errors in using clinical thermometers. $B M \mathcal{Y}$ 1976;i:692.

2 Temperatures and their accuracy. Nursing Times 1971;67:1139.

3 East of Ireland Faculty RCGP and Department of Community Health TCD. How good are we at guessing fever? Irish Med f 1986;79:15-6.

4 Ogren JM. The inaccuracy of axillary temperatures measured with an electronic thermometer. Am f Dis Child 1990;144:101-11.

Norris J. Taking temperatures: the changing state of the art. Contemp Paediatr 1985;2:22-39.

6 Comparing thermometers. Nursing Care 1977;10:14-9.

7 Knapp HA. Accuracy of glass clinical thermometers compared to electronic thermometers. Am f Surg 1966;112:139-41.

8 Ferguson GT, Gohrke C, Mansfield L. The advantages of the electronic thermometer. Hospital 1971;45:62-3.

9 Scholefield JM, Gerba MA, Dwyer P. Liquid crystal forehead thermometer strips. Am $\mathcal{F}$ Dis Child 1982;136:198-210.

10 David CB. Liquid crystal forehead temperature strips. Am $\mathrm{f}$ Dis Child 1983;137:87.

11 Lewit EM, Marshall CK, Salzer JE. An evaluation of a plastic strip thermometer. FAMA 1982;247:321.

12 Martyn KK, Urbano MT, Hayes JS. Comparison of axillary, rectal and skin based temperature assessment in preschoolers. Nurse Pract 1988;13:31.

13 Sharp GB. Fever detector strip criticised, defended. Nurse Pract 1988 July:9. 14 Reisanger KS, Kao J, Grant DM. Inaccuracy of the clinitemp skin thermometer. Paediatr 1979;64:4-6.

15 Shann F, Mackenzie A. Axillary or rectal temperature, in children? Lancet $1981 ; \mathrm{i}: 310$

16 Barrus D. A comparison of rectal and axillary temperatures by electronic thermometer measurements in preschool children. Paediatr Nurse 1983;9: 1010-1.

17 Kresh MJ. Axillary temperatures as a screening test for fever in children. J Paediatr 1984;104:596-9.

18 Banco L, Veltri $D$. Ability of mothers to subjectively assess the presence of fever in their children. Am $\mathcal{F}$ Dis Child 1984;138:976-8.

19 Bergerson PS, Steinfeld MJ. How dependable is palpation as a screening method for fever? Clin Paediatr 1974;13:350-1.
Broomhill Health Centre, South Broomhill, Northumberland NE65 0SR

Paul A Creighton, general practitioner

Angela M Evans, practice nurse

Correspondence to:

Dr Creighton.

BMf 1992;304:963-6

\title{
Audit of practice based cervical smear programme: completion of the cycle
}

\author{
Paul A Creighton, Angela M Evans
}

\begin{abstract}
Objectives-To determine the effectiveness of a practice based cervical screening programme and the changing pattern of abnormal smear results and to improve the quality of care provided for patients.

Design-Audit of practice held data on cervical screening from 1980 to 1990 . Changes in the programme were made after analysis of first five years' data.
\end{abstract}

Setting-Mixed urban and rural practice of 10900 patients in Northumberland.

Subjects - Women aged 20-65 who had not had a hysterectomy.

Results-2356 (85.1\%) of the 2767 targeted women had a test during 1980-5 and $2498(89.5 \%)$ of the 2790 women had a test during 1985-90. Inviting women aged 20-25 to attend for a test increased coverage from $45.8 \%(146 / 319)$ in $1980-5$ to $82.5 \%(282 / 342)$ in 1985-90. The proportion of women with abnormalities requiring hospital referral rose in the second half of the study, especially among younger women (from $17 / 39(44 \%)$ to $45 / 64(70 \%)$ in women aged $25-34)$.

Conclusions-Practice based cervical screening programmes can be highly effective. Cytological abnormalities affect patients psychologically as well as physically and practices should provide support and explanation for patients with abnormal results. Data from individual practices should be aggregated to allow health authorities to plan secondary care effectively.

\section{Introduction}

Over 2000 women every year die of carcinoma of the cervix. In England and Wales there were 13 times as many registrations of carcinoma in situ for $1981-3$ as there were for $1963-5$ in women aged $25-34 .{ }^{1}$ Invasive squamous cell carcinoma of the cervix is responsible for an increasing number of deaths among these younger women. Although most deaths from invasive carcinoma of the cervix occur in women over 60 , in the three years 1986-9, 39 women died of cervical carcinoma in Northumberland, 21 of whom were under $65 .^{2}$

Our practice comprises a partnership of six doctors with one vocational trainee and is responsible for a total list of 10900 patients distributed in a mixed urban and rural area, occupying a $22.5 \mathrm{~km}$ (14 mile) strip of the Northumberland coast. Each doctor operates a personal list system within the umbrella of the partnership. The split site practice has a health centre in the town of Amble (four doctors) and the village of Broomhill (two doctors).

The practice population is stable (less than $5 \%$ turnover) and there has been little increase in the practice list size in the past 40 years. Most of our patients are in social class II-III, with a significant minority in social class $\mathrm{V}$. The area was largely dependent on mining until the closure of Broomhill colliery in 1964. The local miners, who were initially re-employed at smaller local collieries, have gradually become redeployed in the building trade and light industry. The number of long term unemployed people remains higher than the average for the rest of Northumberland.

The practice implemented a comprehensive screening programme for the detection of cervical abnormalities in 1980. The aims of the programme were to reduce the mortality and morbidity from carcinoma of the cervix by ensuring all women aged 25-65 had a cervical smear test once every five years. We conducted this audit to compare the number of women who had a smear test with the number of women targeted by the cervical smear policy to explore our suspicion that 
the number of cytological abnormalities was increasing and to identify how provision of care could be improved.

\section{Subjects and methods}

In 1980 all women aged 25-65 were identified from the age-sex register. Their notes were searched for medical, psychological, and social problems which would have meant screening would be inappropriate. Problems which precluded screening were those that in the opinion of the woman's doctor would make the smear procedure physically or psychologically un pleasant or meaningless to the patient. In addition, the doctor's knowledge of a patient's current social habits often meant that women on holiday, in hospital, or otherwise unavailable were not sent inappropriate invitations.

Women who had had a hysterectomy for benign disease were excluded from the target group. An index card was completed for each woman in the at risk population. As the practice operates an individual list system, a separate card index of these patients was generated for each doctor. The index cards were filed alphabetically in the appropriate year in which the women would be due for recall. The index cards of women with abnormal smear results were filed in a separate area of the appropriate card index.

Women were invited for a smear test by letter once during the five years $1980-5$. Women under 25 years of age who were taking the contraceptive pill were offered a cervical smear opportunistically by their own doctor or at one of the health authority family planning clinics, which occurred fortnightly at each health centre. Copy reports of the smears performed in the family planning clinics were recorded in the practice card index before being passed on to the family planning clinic.

Those who did not attend for a smear after the first invitation received a second letter of invitation that included an offer of an evening appointment. If a woman failed to attend a letter was sent by her own doctor emphasising the importance of a cervical smear test and urging her to attend. Any woman who directly refused any of these invitations was not offered another appointment until her next recall was due, thus respecting the woman's right to make a choice in the matter. The notes of these women were clearly marked to remind the doctor to discuss the importance of a cervical smear with each woman, and to offer a smear, opportunistically. This system proved quite successful, particularly among the younger age group, at subsequent attendances for contraceptive advice.

\section{CHANGES AFTER FIRST AUDIT}

After reviewing our results in 1985 , we felt that the screening method, producing an attendance rate of $85 \cdot 1 \%$ was adequate. Having reviewed current reports ${ }^{3.5}$ on the incidence of carcinoma in situ in younger women, we decided to send invitations to those aged 20-25 years rather than perform smears opportunistically. In addition, after discussions with

TABLE I - Target population and number of women having a smear test fune 1980-7une 1985

\begin{tabular}{|c|c|c|c|c|c|c|c|}
\hline Age & $\begin{array}{l}\text { No of women } \\
\text { registered }\end{array}$ & $\begin{array}{c}\text { No who } \\
\text { had had } \\
\text { hysterectomy }\end{array}$ & $\begin{array}{c}\text { Target } \\
\text { population } \\
\text { at risk }\end{array}$ & $\begin{array}{l}\text { Inappropriate } \\
\text { for screening }\end{array}$ & Direct refusal & $\begin{array}{l}\text { Failed to } \\
\text { attend }\end{array}$ & $\begin{array}{l}\text { No (\%) tested } \\
\text { in five years }\end{array}$ \\
\hline $\begin{array}{l}20-24^{\star} \\
25-34 \\
35-44 \\
45-54 \\
55-65\end{array}$ & $\begin{array}{l}319 \\
744 \\
672 \\
611 \\
613\end{array}$ & $\begin{array}{l}13 \\
57 \\
64 \\
58\end{array}$ & $\begin{array}{l}319 \\
731 \\
615 \\
547 \\
555\end{array}$ & $\begin{array}{r}1 \\
6 \\
10 \\
10\end{array}$ & $\begin{array}{r}16 \\
8 \\
18 \\
32\end{array}$ & $\begin{array}{l}47 \\
17 \\
29 \\
44\end{array}$ & $\begin{array}{l}146(45 \cdot 8) \\
667(91 \cdot 2) \\
584(95) \\
490(89 \cdot 6) \\
469(84 \cdot 5)\end{array}$ \\
\hline Totals & 2959 & 192 & 2767 & 27 & 74 & 137 & $2356(85 \cdot 1)$ \\
\hline
\end{tabular}

^Women aged 20-25 were tested opportunistically. our district medical officer concerning the cytological resources available in the district we decided to offer a cervical smear every three years to women aged 20-35 and every five years to women aged 36-65.

The policy of referral to hospital was rationalised in 1986. Before this women were referred on the advice of the cytopathologist or at the clinical discretion of the doctor. The policy was changed so that any woman with one minor abnormality not requiring referral to hospital (inflammation, atypia, and mild dysplasia) was to be recalled at least annually until she had had negative results for five consecutive years. Thereafter she would be called three yearly. The case notes of any woman with a second abnormal smear result were to be reviewed by her doctor with a view to gynaecological referral, even if the cytopathologist did not suggest referral. Any woman referred back to the care of her general practitioner after hospital treatment for a cervical abnormality was to be tested annually for five years and thereafter three yearly.

The system of communicating cervical cytology results to patients was changed in 1986. Previously patients either left a stamped addressed envelope or telephoned for their results. It was decided to inform all patients of the result of their smear test by a letter generated by the practice.

Further slight amendments to the procedures occurred in 1988 when the practice became computerised. One of us (PAC) created a computer program to facilitate administration of the cervical screening programme. The computer enabled generation of accurate lists of women needing a smear, individual letters of invitation, and monthly printouts listing women with currently abnormal smear results. Printouts were checked against the notes to ensure there was no default from review. Any woman with a serious abnormal result who defaulted from hospital or practice review received a telephone call or was visited at home by the practice nurse. The computer program depends on intelligent and accurate data entry and a protocol is followed when entering data; data on abnormal smear results are entered by a practice nurse. The program has inbuilt checks which search for defaulters and inaccurate and missed data entry.

\section{Results}

\section{JUNE 1980-JUNE 1985}

Of the 2959 women aged $20-65,192$ had had a total hysterectomy (table I). Of the women at risk 27 were judged to be inappropriate for screening, 74 women directly refused to attend, and 137 failed to attend despite two letters of invitation from the practice nurse plus a further letter from their doctor. A total of 2356 women $(85 \cdot 1 \%$ of the at risk population) had a smear test at least once in the five years. Opportunistic testing in women aged $20-25$ resulted in a coverage of $45 \cdot 8 \%$ $(146 / 319)$. These women were all taking oral contraceptives and were encouraged to have a smear by their pill prescriber. Some women had both a smear and a hysterectomy in this five year period. An abnormal smear result is used throughout to denote any report other than a negative result.

Table II shows the number of women who had an abnormal smear result and those who were subsequently referred and who required treatment. Two women died in these five years. The first woman died of invasive carcinoma of the cervix, stage IIA. Histological examination showed this to be a poorly differentiated squamous cell carcinoma of the cervix. This 53 year old woman had presented with an episode of postmenopausal bleeding, which she had failed to report for eight months. She had had a negative smear test result four years before this episode. The second woman, aged 61 , presented with postmenopausal 
TABLE II-Number (percentage) of women with abnormal smear results who were referred to hospital and required treatment

\begin{tabular}{ccrrrrrrr}
\hline & \multicolumn{3}{c}{ June 1980-June 1985 } & & \multicolumn{3}{c}{ July 1985-July 1990 } \\
\cline { 2 - 5 } \cline { 6 - 8 } & $\begin{array}{c}\text { Abnormal } \\
\text { result }\end{array}$ & Referred & Treated & & $\begin{array}{c}\text { Abnormal } \\
\text { result }\end{array}$ & Referred & Treated \\
\hline $20-24$ & 9 & $5(56)$ & $3(33)$ & & 40 & $30(75)$ & $21(53)$ \\
$25-34$ & 39 & $17(44)$ & $12(31)$ & & 64 & $45(70)$ & $34(53)$ \\
$35-44$ & 33 & $18(55)$ & $14(42)$ & & 37 & $22(59)$ & $19(51)$ \\
$45-54$ & 19 & $8(42)$ & $7(37)$ & & 21 & $12(57)$ & $11(52)$ \\
$55-64$ & 7 & $4(57)$ & $2(29)$ & & 10 & $6(60)$ & $4(40)$ \\
\hline Total & 107 & $52(49)$ & $38(36)$ & 172 & $115(67)$ & $89(52)$ \\
\hline
\end{tabular}

bleeding three years after a negative smear result. The cervical smear showed endometrial cells and the histology confirmed a well differentiated adenocarcinoma of the endometrium, infiltrating the myometrium of the fundus of the uterus. She died of complications after radiotherapy.

JULY 1985-JULY 1990

Of the 3115 women aged 20-65, 325 had had a hysterectomy (table III). Some women had both a smear test and a hysterectomy in this five year period. Of the at risk population 22 were judged to be inappropriate for screening, 61 directly refused to attend, and 209 failed to attend despite two letters of invitation from the practice nurse plus a further letter from their doctor. In all, 2498 women $(89.5 \%$ of the at risk population) had a smear test in the five years, including 282 women aged $20-25(82 \cdot 5 \%$ of the at risk population).

Table II shows the number of women by age group who had an abnormal smear recall, and those subsequently referred to hospital and who required treatment. Six of the 11 women in the age groups 20-34 who were referred to hospital with two mildly abnormal smear results (inflammation, borderline nuclear changes, or atypia or dysplasia) subsequently needed treatment after abnormal cervical biopsy results. In one of these women, whose second smear was reported as showing inflammatory change, histological examination found cervical intraepithelial neoplasia stage II with gland extension. A second woman, whose second smear showed borderline nuclear changes, also had cervical intraepithelial neoplasia stage II diagnosed. A third woman was referred after having two smears showing borderline nuclear changes. Subsequent histological examination showed an adenocarcinoma of the cervix, and she was successfully treated with a cone biopsy. These women justified our policy of referral after two abnormal smears, regardless of the severity of the lesion.

In the age groups 35-65 most women were referred because of a more severe cytological abnormality. Of the two other cases of successfully treated carcinoma of the cervix, one woman presented at the beginning of this five year period with clinical carcinoma of the cervix. She had had a negative smear result (with inflammatory changes) three years previously but had failed to report a postmenopausal bleed which had occurred 18 months previously. The other woman, aged 65, came for a routine recall, having had a norma smear result five years previously.

TABLE III -Target population and number of women having a smear test, fuly 1985-fuly 1990

\begin{tabular}{lccccccc}
\hline Age & $\begin{array}{c}\text { No of women } \\
\text { registered }\end{array}$ & $\begin{array}{c}\text { No who } \\
\text { had had } \\
\text { hysterectomy }\end{array}$ & $\begin{array}{c}\text { Target } \\
\text { population } \\
\text { at risk }\end{array}$ & $\begin{array}{c}\text { Inappropriate } \\
\text { for screening Direct refusal }\end{array}$ & $\begin{array}{c}\text { Failed to } \\
\text { attend }\end{array}$ & $\begin{array}{c}\text { No (\%) tested } \\
\text { in five years }\end{array}$ \\
\hline $20-24$ & 342 & & 342 & 1 & 2 & 57 & $282(82 \cdot 5)$ \\
$25-34$ & 756 & 10 & 746 & 6 & 6 & 61 & $673(90 \cdot 2)$ \\
$35-44$ & 775 & 67 & 708 & 5 & 7 & 29 & $667(94 \cdot 2)$ \\
$45-54$ & 640 & 116 & 524 & 4 & 14 & 20 & $486(92 \cdot 7)$ \\
$55-65$ & 602 & 132 & 470 & 6 & 32 & 42 & $390(83)$ \\
\hline Total & 3115 & 325 & 2790 & 22 & 61 & 209 & $2498(89 \cdot 5)$ \\
\hline
\end{tabular}

One woman died in this five year period from invasive squamous cell carcinoma of the cervix. She was aged 64 and had been invited to attend for a cervical smear on several occasions but had declined.

\section{Discussion}

We have completed the audit cycle once. This does not mean that the audit of the smear programme is complete but it shows the benefits to patients that can accrue if audit is consistently applied.

During this audit many new problems surrounding the quality of the care being given to our patients came to light. For example, the changes in referral and patient communication policy generated some anxiety among women who had an abnormal smear result. This was reflected in women making appointments to see their doctor to discuss the significance of an abnormal smear result or a hospital referral. To help these women the practice prepared literature which explained the term "abnormal smear" and gave a glossary of terms they might subsequently encounter (colposcopy, cryotherapy, etc). This literature was offered to any woman expressing anxiety at a routine smear appointment. The practice nurse offered appointments to explore anxieties and explain terminology and procedures. The programme has required many changes since its inception and has entailed many hours of discussion between the partners and the practice nurse. The cervical smear protocol is now reviewed every two years.

As in any effective screening programme coordination and communication are vital, and although the ultimate responsibility lies with the doctor, the responsibility for running the screening programme (administration and taking smears) has been delegated to a practice nurse (AME), working closely with one partner. The success of this nurse run clinic is in line with the experience of others. ${ }^{\text {? }}$

The programme has attempted to raise women's awareness about the nature of a cervical smear test, to reduce their anxiety during the taking of the smear, and always to inform them of their cervical smear result. We believe that this programme, implemented and based in general practice, is more effective than a district health authority call and recall programme. It is certainly more easily audited, more personal, and more sensitive to women's needs.

\section{CYTOPATHOLOGICAL CLASSIFICATION}

The cytopathological and histological reporting of cervical smear abnormalities have changed during the past 10 years. During $1980-5$ the terms atypia (mild, moderate, or severe) and dysplasia were used in cytological reporting and carcinoma in situ was the histological term used to indicate changes affecting the full thickness of cervical epithelium without invasion of local structures. In 1986 the term cellular intraepithelial neoplasia was introduced to indicate cell changes restricted to the epithelium. ${ }^{6}$ The new classification is more descriptive of the cell changes seen by the cytologist. It is not possible accurately to substitute terms used in the two periods of this audit. The increased number of abnormal smears noted in the second audit may be due either to an increased incidence of cellular intraepithelial neoplasia or to the different way of reporting abnormalities.

\section{EFFECTS OF CHANGING POLICY}

The decision to invite women aged $20-25$ by letter, resulted in an increase, from $45.8 \%$ to $82.5 \%$ of that age group, having a smear test. No firm conclusions can be drawn from the increase in abnormal smear results in this age group because of the different numbers of women smeared. 
The number of abnormal smear results increased from 39 to 64 in women aged 25-34. We also noted that the percentage of women with abnormal smear results who were subsequently treated in the second five year period was higher in all age groups than during the first five year period.

\section{IMPLICATIONS}

Our results have important implications relating to the government policy to remunerate general practitioners for screening performed at five yearly intervals. This policy means that most women in the United Kingdom have a smear test once every five years, as performing smears more often than this conveys a financial disadvantage to general practitioners. Twenty six women in the age group 25-34 who had developed cytological changes reported as cellular intraepithelial neoplasia I, II, or III had had a negative smear result in the preceding three years. This suggests a progression from normal to abnormal cytology in less than five years.

Hospital investigation and care of women with cytological abnormalities is likely to increase as more practices achieve the higher targets in cervical screening. Planning for the provision of this care would benefit from accumulated general practice data provided by audits such as ours. Family health services authorities should facilitate the aggregation of data which are currently held on diverse computer systems in neighbouring practices and should make them available to the health authority managers and doctors planning and providing secondary care. It has been proposed that the managerial systems of primary and secondary health care be integrated.$^{8}$ If the model suggested here was adopted, with primary care measuring the health needs of the population and secondary care being developed to respond to those needs the health service would move to being a patient centred service.

1 Duncan ID. Colposcopy and treatment of the abnormal cervical smear. Update 1989;38:1107-14.

2 Director of Public Health. Health in Northumberland. Northumberland: Northumberland Health Authority, 1989.

3 Draper GJ. Screening for cervical cancer: revised policy. The recommendation of the DHSS committee on gynaecological cytology. Health Trends 1982;14 $37-40$

4 International Agency for Research on Cancer Working Group on Evaluation of Cervical Cancer Screening Programmes. Screening for squamous cervical cancer: duration of low risk after negative results of cervical cytology and its implication for screening policies. BMF 1986;293:659-64.

5 Paterson MEL, Peel KR, Joslin CAF. Cervical smear histories of 500 women with invasive cervical cancer in Yorkshire. BMF 1986;289:896-8.

6 Evans DMD, Hudson EA, Brown CL, Boddington MM, Hughes HE Mackenzie EF, et al. Terminology in gynaecological cytopathology: report of the Working Party of the British Society for Clinical Cytology. I Clin Pathol 1986;39:933-44.

7 Jewell D, Hope J. Evaluation of a nurse-run hypertension clinic in genera practice. Practitioner 1988;232:484-7.

8 NHS Management Executive. Integrating primary and secondary health care. London: NHS Management Executive, 1991. (EL(91)27.)

(Accepted 20 January 1992) 